\title{
Migração brasileira para a área metropolitana de Lisboa nos últimos dez anos ${ }^{1}$
}

\author{
Brazilian migration to the metropolitan area of \\ lisbon in the last ten years
}

\section{Onofrio Di Spirito $*^{1}$}

Palavras-chave:

Fluxos migratórios; Migração de brasileiros; Área metropolitana de Lisboa.

Keywords: Migratory flows; Brazilian migration; Lisbon metropolitan area
Resumo: $O$ presente estudo apresenta dados teóricos e estatísticos relativos à imigração de brasileiros para a Área Metropolitana de Lisboa (AML) nos últimos dez anos. Dentre os imigrantes residentes em Portugal, os brasileiros constituem maioria. O problema de pesquisa consiste em determinar os motivos ensejadores da imigração. A pesquisa valeu-se do método de observação das referências já escritas sobre o tema e o método estatístico, que possibilitou a quantificação dos dados apresentados por entidades oficiais. Conclui-se pelo crescimento do número de imigrantes brasileiros na $A M L$, o que não indica, todavia, surpresa, na medida em que os números históricos já revelavam a preponderância de brasileiros na região. As perspectivas são de continuidade dos fluxos migratórios, especialmente após a normalização dos deslocamentos internacionais no pós-pandemia.

\begin{abstract}
This study presents theoretical and statistical data on Brazilian immigration to the Lisbon Metropolitan Area (AML) in the last ten years. Among immigrants residing in Portugal, Brazilians are the majority. The research problem is to determine the causes of immigration. The research used the method of observation of references already written on the subject and the statistical method, which enabled the quantification of data presented by official entities. The conclusion is that there is a growth in the number of Brazilian immigrants in the $A M L$, what is not surprising, because previous data already revealed the preponderance of Brazilians in the region. Perspectives are for the continuity of migratory flows, especially after the normalization of international movements in the post-pandemic.
\end{abstract}

\footnotetext{
${ }^{1}$ Recebido em 15/12/2020. Aceito em 19/03/2021.

${ }^{* 1}$. Doutorando em Estudos Migratórios; bacharel em Relações Internacionais, Universidade de Granada. E-mail: onofrio.dispirito@hotmail.it.
} 


\section{Introdução}

O presente artigo tem como objetivo geral analisar o fluxo imigratório de brasileiros para a Área Metropolitana de Lisboa nos últimos dez anos. Imprescindível conhecer a quantificação, causas e andamento desse fluxo imigratório. Para tanto, realizou-se pesquisa documental e estatística em fontes secundárias e dados apresentados por instituições oficiais relativas ao tema.

O estudo tem como premissa responder à problemática: quais razões levaram à imigração de brasileiros para a Área Metropolitana de Lisboa nos últimos dez anos? A hipótese inicial prevista reside, por um lado, na instabilidade econômica, desemprego e alta criminalidade vivenciada pelos brasileiros nos últimos anos e, por outro, no fato de Portugal ser visto como país atrativo, sobretudo por sua estabilidade político-econômica.

Para alcance do objetivo proposto, o estudo apresenta aspectos teóricos e estatísticos relativos à emigração de brasileiros para Portugal. Esboça o perfil dos emigrantes brasileiros, os postos de trabalho ocupados e outros pontos relevantes, tendo como ênfase a Área Metropolitana de Lisboa (AML), no período compreendido entre 2011 e 2021.

\section{Metodologia}

O estudo pretende avaliar aspectos referentes à imigração brasileira para Portugal, especificamente para a Área Metropolitana de Lisboa (AML), nos últimos dez anos. Para alcance dos fins almejados, realizou-se pesquisa do tipo aplicada, em busca de hipótese(s) para o problema levantado, qual seja, conhecer as razões que levaram brasileiros a escolherem a AML como lugar de residência. A pesquisa aplicada tem por natureza auxiliar na construção de conhecimentos, com vistas à resolução de problemas específicos (PRODANOV; FREITAS, 2013).

Os métodos utilizados foram o de observação e o estatístico. Analisou-se as referências já escritas sobre o tema migração de brasileiros para Portugal, sobretudo para a $A M L$, e a quantificação dos dados apresentados pelas

Caderno Eletrônico de Ciências Sociais, Vitória, v. 9, n. 1, pp. 68-91, 2021. 
entidades oficiais portuguesas e europeias nos últimos dez anos. Em pesquisas sociais, por vezes, necessário se faz recorrer a mais de um procedimento. 0 método de observação possibilita a interpretação subjetiva do objeto estudado, enquanto o estatístico reforça as conclusões obtidas. Desse modo, na fase de seleção, foi realizado exame minucioso das referências descritas sobre o tema, com vistas a eliminar informações confusas, imprecisas, distorcidas ou de fontes não confiáveis. A etapa seguinte consistiu na análise dos dados obtidos, momento em que o autor apresenta os resultados alcançados, correlacionandoos com explicações teóricas acerca dos mesmos (GIL, 2008; RODRIGUES et al., 2011).

Como parâmetro para a fundamentação teórica, o estudo valeu-se da literatura nacional e internacional sobre o tema, como livros, artigos, dissertações e teses. Tais embasamentos foram validados por informações obtidas pelos Banco de Dados da Organização para a Cooperação e Desenvolvimento Econômico (OCDE), do Instituto Nacional de Estatística (INE) e do Serviço de Estrangeiros e Fronteiras (SEF), tendo por amostra imigrantes brasileiros em Portugal, de modo geral, e na $A M L$, de modo específico, no período compreendido entre 2011 e 2020.

Quanto ao método de abordagem do problema, a pesquisa classifica-se como quantitativa e qualitativa. As molas propulsoras da análise qualitativa das fontes secundárias são as palavras, as ideias, as opiniões particulares de cada autor sobre o tema em estudo. A análise quantitativa, por sua vez, permite o tratamento objetivo da amostra pesquisada, a partir da delimitação do grupo social a ser estudado, com avaliação das suas principais características, importância, variação ou qualquer outro elemento que auxilie na compreensão do grupo social delimitado (LAKATOS; MARCONI, 2017).

\section{Aspectos teóricos sobre a migração de brasileiros para Portugal}

A emigração é fator recorrente na história do Brasil. Diversos são os motivos ensejadores à saída de cidadãos brasileiros para outros países, como falta de segurança, educação e saúde precárias e a crise econômica que tem

Caderno Eletrônico de Ciências Sociais, Vitória, v. 9, n. 1, pp. 68-91, 2021. 
afetado o país nos últimos anos. Indivíduos de classes menos favorecidas e cidadãos abastados têm recorrido a outras nações em busca de melhores condições de vida. Segundo informações da Receita Federal brasileira, em 2018, 23.149 cidadãos entregaram a declaração de saída definitiva do país. Desde 2014, a entrega dos comunicados por indivíduos que decidem morar no exterior tem aumentado sobremaneira, sendo fatores preponderantes citados a violência, a insegurança político-econômica, a corrupção e a baixa qualidade de vida. Até 2014, as saídas definitivas declaradas não passavam dos 10 mil (GERBELLI, 2019; AYER, 2019).

O Sistema de Tráfego Internacional, plataforma da Polícia Federal responsável pelo registro dos fluxos de entrada e saída de pessoas no Brasil, contabilizou, em 2019, 115.422 cidadãos que deixaram o país e não voltaram. Em 2018, o saldo também foi negativo em 126.306. Credita-se esse fenômeno de emigração, similar ao que aconteceu nas décadas de 1980 e 1990, ao desapontamento e à falta de perspectivas do brasileiro quanto a um futuro melhor em seu país natal, diante da recessão econômica enfrentada em 2015 e 2016, cujos reflexos perduram aos dias atuais, manifestados, principalmente, pelo desemprego recorde. O PIB brasileiro em 2020 foi negativo em 4,1\%, o menor desde 1996. Quanto à taxa de desemprego, de julho a setembro de 2020, o índice alçou o patamar de 14,6\%, um dos maiores já registrados pelo Instituto Brasileiro de Geografia e Estatística, desde 2012 (NAKAGAWA, 2021; BRASIL, 2021).

A violência é argumento comumente apresentado por aqueles que decidem deixar o Brasil em definitivo. Na última década, o número de crimes letais - homicídio doloso, latrocínio e lesão corporal seguida de morte - no Brasil tem apresentado constante evolução. Em 2011, o monitor da violência registrou 48.084 crimes violentos, uma taxa de 25,0 mortes para cada grupo de 100 mil habitantes. Em 2014, esse número subiu para 57.091, elevando a taxa para 28,2. Em 2017, foram computados, em todo o território nacional, 59.128 crimes violentos, o que corresponde a 28,5 - índice por 100 mil habitantes. Tratandose de unidades federativas com maiores taxas de letalidade por crimes

Caderno Eletrônico de Ciências Sociais, Vitória, v. 9, n. 1, pp. 68-91, 2021. 
violentos, Estados das regiões norte e nordeste do Brasil assumem as colocações mais elevadas, com taxas entre 49 e 71,9 crimes letais para grupos de 100 mil habitantes. A guerra entre facções criminosas pelo controle do tráfico internacional das drogas é um dos fatores que cooperam à alta letalidade nessas regiões (G1, 2021; BRASIL, 2020).

A sensação de insegurança, em face dos índices de criminalidade no Brasil, acomete não apenas os nativos, mas desperta a atenção internacional. Acredita-se que a corrupção e a criminalidadade estejam enraizadas na cultura brasileira. Os próprios cidadãos buscam subterfúgios para beneficiarem-se às custas de outrem ou dão menor relevância àquilo que traz prejuízos a terceiros. Existe a percepção de que as cidades são perigosas, onde a delinquência, muitas vezes, é praticada à luz do dia, sendo possível ouvir troca de tiros, tráfico nas ruas, abordagem policial agressiva, assaltos a transporte público, "toque de recolher", em certos horários e regiões, deteminado por facções criminosas. Soma-se a isto, a exposição massiva, e repetitiva, da mídia popular e policial, de casos violentos e a própria experiência individual como vítima de violência ou de crimes como fatores que contribuem à sensação de que o país não é seguro e o cidadão encontra-se desprotegido. Conforme Pereira (2019, p. 30-32), "para muitos, a ideia que fica é de caos absoluto, de risco constante, mesmo que para a maioria a vulnerabilidade ao crime ou à violência não seja realmente significante."

Com vistas à compreensão das razões ensejadoras da emigração de brasileiros para Portugal, sobretudo a Área Metropolitana de Lisboa, importante mencionar os três marcos históricos-contemporâneos que levaram a tal fluxo migratório. No primeiro período, o fluxo migratório ocorreu na década de 1980, quando Portugal tornou-se membro da Comunidade Econômica Europeia, em 1986. Na ocasião, portugueses que haviam deixado o país com seus familiares, bem como brasileiros que mantinham com aqueles alguma relação social, voltaram para Portugal, em razão do descontrole inflacionário e da insegurança política, econômica e social gerada no Brasil. O segundo fluxo ocorreu em meados da década de 1990, quando Portugal passou a ser visto como um país

Caderno Eletrônico de Ciências Sociais, Vitória, v. 9, n. 1, pp. 68-91, 2021. 
atrativo, seja pelos seus avanços, seja por fazer parte da União Europeia. O terceiro período, com início no final da década de 1990 e que perdura até o presente momento, é marcado pelo rígido controle das fronteiras, evidenciando o número expressivo de brasileiros, antes em situação irregular, em busca de autorizações de permanência no país, pelo processo de regularizações extraordinárias (PINHO, 2014; JOÃO, 2013).

A estabilidade político-econômica de Portugal na década de 1990 contribuiu à injeção de capital estrangeiro no país, o que levou à ampliação das suas obras públicas, consequente aumento da oferta de empregos, principalmente na área da construção civil. Ressalta-se, contudo, a busca por trabalhadores para realização dos mais diversos tipos de atividades, em setores de hotelaria, limpeza e comércio em geral. Hoje, o setor de serviços e comércio de produtos é o responsável pela maior parte das vagas de emprego disponibilizadas. A população brasileira residente, em função da sua simpatia e domínio do idioma, é a que maior apresenta diversidade de ocupações. Nesse cenário, a emigração de brasileiros para Portugal se deu em razão das regularizações extraordinárias concedidas pelo Estado em 1992 e 1996 e pela autorização de permanência instituída em 2001, que possibilitou a regularização da situação dos trabalhadores clandestinos, posto que o país carecia de mão-de obra, situação que levou ao crescimento do número de estrangeiros imigrantes. Os acordos bilaterais entre Portugal e os Países de Língua Oficial Portuguesa (PALOP) e o Brasil é fator que contribui à legalização dos estrangeiros que desejam exercer atividade laboral no país (JOÃO, 2013).

Justamente em razão dos processos de regularização, o volume exato de ingressos anuais não é conhecido. A teoria acerca da migração brasileira para Portugal, no entanto, indica que muitos imigrantes são, em realidade, turistas que passaram um tempo em situação irregular no país, aproveitando as oportunidades de regularização legal. Assim, as oscilações no fluxo de migrantes brasileiros se devem, em especial, às alterações legislativas. 0 aumento do número de brasileiros que migram para Portugal é relevante, tendo em vista que o fluxo mais intenso se deu em um período de reduzido

Caderno Eletrônico de Ciências Sociais, Vitória, v. 9, n. 1, pp. 68-91, 2021. 
crescimento econômico. Com o pouco crescimento dos postos laborais, outros fluxos migratórios experimentaram declínio, ao passo que a imigração brasileira permaneceu em alta. Algumas das explicações teóricas para esse fluxo são a regularização, o custo elevado de outros destinos, como os Estados Unidos, e a influência das redes sociais no processo de tomada de decisão (NUNAN; PEIXOTO, 2012).

Acerca das redes sociais, ou "redes migratórias", como elemento de influência do processo de migração, compreendem-se, na acepção de Massey (1988, p. 396), como "complexos de laços interpessoais que ligam migrantes, migrantes anteriores e não-migrantes nas áreas de origem e de destino, por meio de vínculos de parentesco, amizade e conterraneidade." A decisão pela saída do país de origem, desse modo, ocorre após canalização da experiência relatada por aqueles com quem mantém algum grau de proximidade. A migração é precedida de informações sobre as oportunidades e os desafios a serem experimentados no local de destino, como oferta de trabalho, educação, segurança, saúde, dentre outros. Nesse viés, os laços sociais familiares, a rede de parentesco, o agrupamento de amigos e outros laços sociais exercem grande impacto nesses processos migratórios

Truzzi (In: Lanna et al., 2011, p. 203) explica as circunstâncias que levaram ao uso dos termos "cadeias" e "redes" e o modo como elas estimulam o comportamento de novos migrantes:

o emprego dos termos cadeias e redes, em suas acepções mais restritas ou abrangentes, procura sublinhar a circunstância de que muitos decidiam emigrar após informarem-se previamente das oportunidades (e dificuldades) com imigrantes anteriores, seja por carta, seja quando retornavam. Estes podiam prover tanto informações, no tocante às perspectivas de emprego e alojamento iniciais, como recursos, por meio de remessas monetárias, que pudessem financiar e assim viabilizar a viagem. Cabe, nesse sentido, sublinhar o papel ativo dos emigrados na sociedade de origem, de modo a influenciar o comportamento de novos migrantes potenciais, estimulando ou refreando projetos, expectativas e investimentos futuros.

Outros elementos, como os laços históricos e a proximidade cultural, exerceram grande papel no fluxo migratório. Esses elementos foram

Caderno Eletrônico de Ciências Sociais, Vitória, v. 9, n. 1, pp. 68-91, 2021. 
determinantes para o volume de imigrantes e responsáveis pela inserção de brasileiros no mercado de trabalho português. A imigração pode ser dividida, para fins de estudo, em três grandes fluxos. O primeiro deles, em meados dos anos 1980, foi representado por um pequeno número de imigrações, ao mesmo tempo em que esses imigrantes eram altamente qualificados em termos profissionais, sendo inseridos em áreas como a publicidade, a informática e a medicina dentária. O segundo fluxo migratório, mais expressivo, foi direcionado para áreas como a construção civil, serviços domésticos, cuidados e similares. Por fim, o fluxo imigratório que teve início no final da década de 1990 e que se arrasta até os dias atuais atingiu segmentos menos qualificados, que passaram a atuar em áreas como serviços pessoais, proteção, segurança e vendas. No mercado informal, os brasileiros tiveram sucesso especialmente nas atividades comerciais, valendo-se de suas habilidades para o contato direto com os clientes (PEREIRA; ESTEVES, 2017).

A inserção de brasileiros no mercado de trabalho no contexto do processo de imigração, no segundo fluxo migratório, o setor secundário do mercado de trabalho português foi o mais beneficiado. A nova força de trabalho se submeteu a estatutos jurídicos deficientes e condições laborais ruins. Lisboa (2016) menciona que, além do trabalho irregular em campos como a da construção civil, muitas brasileiras buscaram a prostituição como meio de adaptação ao contexto do novo país. Existem teorias acerca da relação entre os postos de trabalho e os fluxos migratórios para Portugal, incluindo de brasileiros e outros imigrantes.

As teorias das migrações internacionais auxiliam na compreensão do movimento migratório de brasileiros para Portugal. Segundo Muniz (2002), a decisão pela saída do país de origem para outro, tendo como objetivo a busca por melhores condições de vida, após análise do custo-benefício da ação, enquadra-se no modelo migratório neoclássico. Esse modelo reveste-se de subjetividade e origina-se de uma análise individual micro, partindo-se da ideia de que as perdas inerentes ao movimento de saída do país serão compensadas pelos ganhos obtidos na nação-destino.

Caderno Eletrônico de Ciências Sociais, Vitória, v. 9, n. 1, pp. 68-91, 2021. 
Para Massey et al. (1998), o modelo neoclássico de migração internacional proporciona equilíbrio econômico entre os países. Sempre em busca de maximização da renda, há um deslocamento de indivíduos de nações onde os salários são baixos para nações que propiciam maiores ganhos. Tal situação leva os países destinos a baixarem os salários, em razão da alta oferta de mão-de-obra provocada pelo fluxo trabalhista, e os países de origem a aumentarem os salários, pela necessidade trabalhadores. Referido modelo resultou na teoria push-pull, que analisa os fluxos migratórios a partir dos elementos de expulsão e atração, entre os países de origem e destino. Como fatores de expulsão do indivíduo do país de origem citam-se baixos salários, baixa qualidade de vida, serviços essenciais precário, dentre outros. Noutro lado, países com acesso à terra, emprego, boa remuneração, educação, saúde etc. atuam de modo a atrair os indivíduos para si.

No modelo histórico-estrutural, a migração ocorre por fatores macros, associados a questões sociais, políticas e econômicas enfrentadas pelo indivíduo. De acordo com Laraña (1993), nesse modelo, o fluxo migratório é examinado a partir das lutas entre diversos setores sociais, geradoras de situações de conflito, exploração e desigualdade. Muniz (2002) cita que o fluxo migratório também pode ocorrer sob influência domiciliar (familiar). Aqui, o indivíduo, embora racionalize individualmente, no primeiro instante, tem o apoio familiar na tomada de decisão e ajustes necessários, com vistas a evitar prejuízos de qualquer ordem e a minimizar as dificuldades naturais do processo migratório.

Para Garcia (1993), a preparação faz parte em todos os tipos de fluxos migratórios. Consiste em uma etapa onde o indivíduo, sozinho ou com o apoio familiar, analisa as condições relativas ao ato de saída do país de origem, como deslocamento, meio de transporte, recursos necessários, dentre outros. Avalia as condições sociodemográficas, políticas e econômicas do país destino, assim como será a interatividade com os seus cidadãos. É uma preparação dolorosa e que desperta muitos sentimentos no indivíduo. Há o contraponto de emoções. A tristeza por deixar o país onde nasceu e cresceu, o medo pelo desconhecido e a 
ansiedade pelo que encontrará pela frente. $O$ choque entre a realidade que vive e os desafios a serem superados para alcance do futuro almejado. Experiências relatadas por pessoas que passaram pelo mesmo processo, fazem-no, muitas vezes, questionar se emigrar é realmente um ato necessário. Igualmente, há um ressentimento por sentir-se compelido a deixar seu país por não encontrar oportunidades e visualizar cidadãos que vivem em boas condições e não precisam deixar sua terra.

Consoante Patarra (2006), a globalização é outro fator associado ao fluxo migratório internacional, nos últimos anos. As transformações econômicas, políticas e sociais pelas quais o mundo tem vivenciado contribuíram para o aumento da saída de indivíduos dos seus países de origem. Grande parte disso se deve aos avanços nos meios de produção e a acumulação de capital dos países desenvolvidos e em desenvolvimento. Para Sassen (1998), as cidades globais despertam interesse, em razão expansão industrial e econômica, da oferta de trabalho com bom retorno financeiro e serviços avançados. 0 indivíduo de países mais pobres sente-se excluído, compelido, de certa forma, a deixar o seu país, pela falta de recursos e oportunidades. Com isso, vê a possibilidade de construir um futuro melhor em nações mais desenvolvidas política, econômica e socialmente.

De acordo com Oliveira et al. (2017), como razão dos novos fluxos migratórios está o sentimento de que o indivíduo não colabora com a produção econômica do país de origem. Em busca de qualidade de vida, recorre a países em que sua mão-de-obra será valorizada. A presença de brasileiros para Portugal tem gerados impactos positivos no país anfitrião, sobretudo no campo sociocultural. Costa (2011) afirma que os brasileiros têm encontrado em Portugal a qualidade de vida esperada e são vistos pelos nativos como imigrantes afetos e positivos. Em seu estudo, a escolha dos brasileiros por Portugal como país destino deu-se, em primeiro lugar, pelo idioma e a facilidade de comunicação oral e escrita.

É possível compreender a relação entre globalização e fluxo migratório a partir da disparidade da distribuição internacional de renda e os reflexos sobre os mercados de trabalho, situação que cria um distanciamento, em termos de

Caderno Eletrônico de Ciências Sociais, Vitória, v. 9, n. 1, pp. 68-91, 2021. 
estabilidade econômica e estrutura demográfica, entre o norte e o sul do globo. A expansão do capitalismo tem levado grandes multinacionais para os países de origem do fluxo migratório, geralmente os mais pobres, em busca de mão de obra barata, baixos impostos, matéria-prima, ocasionando uma desconexão entre as regiões onde são instaladas e outros circuitos mundiais. Enquanto isso, os países de destino continuam vistos com maior atratividade, também pela consciência da importância que o trabalho estrangeiro fornece para o bem-estar da nação (ABAD, 2002).

Contudo, não são apenas as condições econômicas que levam as pessoas a escolherem outras nações para viverem. Questões sociopolíticas também influenciam o fluxo migratório e estão relacionadas pela intolerância e intransigência estatal em assuntos religiosos, raciais, étnicos, que geram situação de guerras e conflitos entre os cidadãos, levando pessoas a sentiremse deslocadas, sozinhas, em busca de exílio ou refúgio. Situações como o "11 de setembro de 2001", nos Estados Unidos, e a guerra contra o Iraque, a partir do evento, os conflitos entre grupos políticos e religiosos, no Oriente Médio, os atentados contra europeus praticados por imigrantes muçulmanos são exemplos de situações sociais que forçam muitos indivíduos a buscarem refúgio em outros países. Ademais, o boom da emigração tem ocasionado conflitos em decorrência de atos de racismo e xenofobia que o imigrante enfrenta no país destino (PATARRA, 2006; BLANCO, 2000).

Em continuidade, acredita-se que a imagem que possui o cidadão português em relação ao brasileiro tenha colaborado para o surgimento de mercados próprios, de forma a incorporar uma identidade brasileira no mercado de trabalho de Portugal. O brasileiro é visto como um povo de sorriso largo, sensual e até mesmo esperto. Lisboa (2016, p. 5) esclarece que a influência do imaginário português sobre o brasileiro contribuiu à criação de mercados de trabalho próprios para tais estrangeiros, corroboradas não apenas pela mídia, mas também pelas indústrias brasileiras atuantes em Portugal:

[...] o conjunto de representações estereotipadas do Brasil amolda determinados "tipos" de emprego exclusivos aos imigrantes

Caderno Eletrônico de Ciências Sociais, Vitória, v. 9, n. 1, pp. 68-91, 2021. 
brasileiros em Portugal, que são direcionados a atividades em estabelecimentos comerciais, como bares, restaurantes, hotéis e casas noturnas, onde se exige que os funcionários desdobrem-se em simpatia no contato direto com os clientes.

Necessário anotar que o processo de imigração de brasileiros continua. Há teorias que indicam, inclusive, a existência de um quarto fluxo migratório. $\mathrm{O}$ fluxo migratório mais recente teria se iniciado em 2015, chegando ao seu fim, de forma prematura, no início de 2020, por força das restrições sanitárias impostas pela pandemia do Covid-19. Esse, talvez, tenha sido o fluxo mais volumoso e variado de brasileiros das últimas décadas (FERNANDES et al., 2021).

O Brasil ocupa, hoje, a $17^{a}$ posição entre as nações que mais enviam brasileiros para nações desenvolvidas, de acordo com dados obtidos pela OCDE. Somente em 2017, 99 mil brasileiros migraram para um dos países do "clube dos países ricos", constituindo um aumento de $24 \%$, comparado ao levantamento feito em 2016 (FERNANDES, 2019).

Entre 2011 e 2019, a OCDE contabilizou a imigração de 688.612 brasileiros para um dos seus 37 Países-Membros. De acordo com dados obtidos em 2021, nesta ordem, Estados Unidos (17,3\%), Japão (13,03\%), Portugal $(12,98 \%)$, Itália $(10,75 \%)$, Espanha $(10,15 \%)$, Alemanha $(9,76 \%)$, França $(4,04 \%)$, Canadá $(3,23 \%)$, Suíça $(2,49 \%)$, Países Baixos $(2,43 \%)$ e Austrália $(1,89 \%)$ foram as preferências na escolha dos brasileiros quanto à imigração, nos últimos dez anos. Somente nos 12 países citados, a organização internacional registrou 622.896 imigrantes brasileiros, conforme demonstra o Gráfico I:

Gráfico I: Países com maior número de imigrantes brasileiros na OCDE (20112019). 


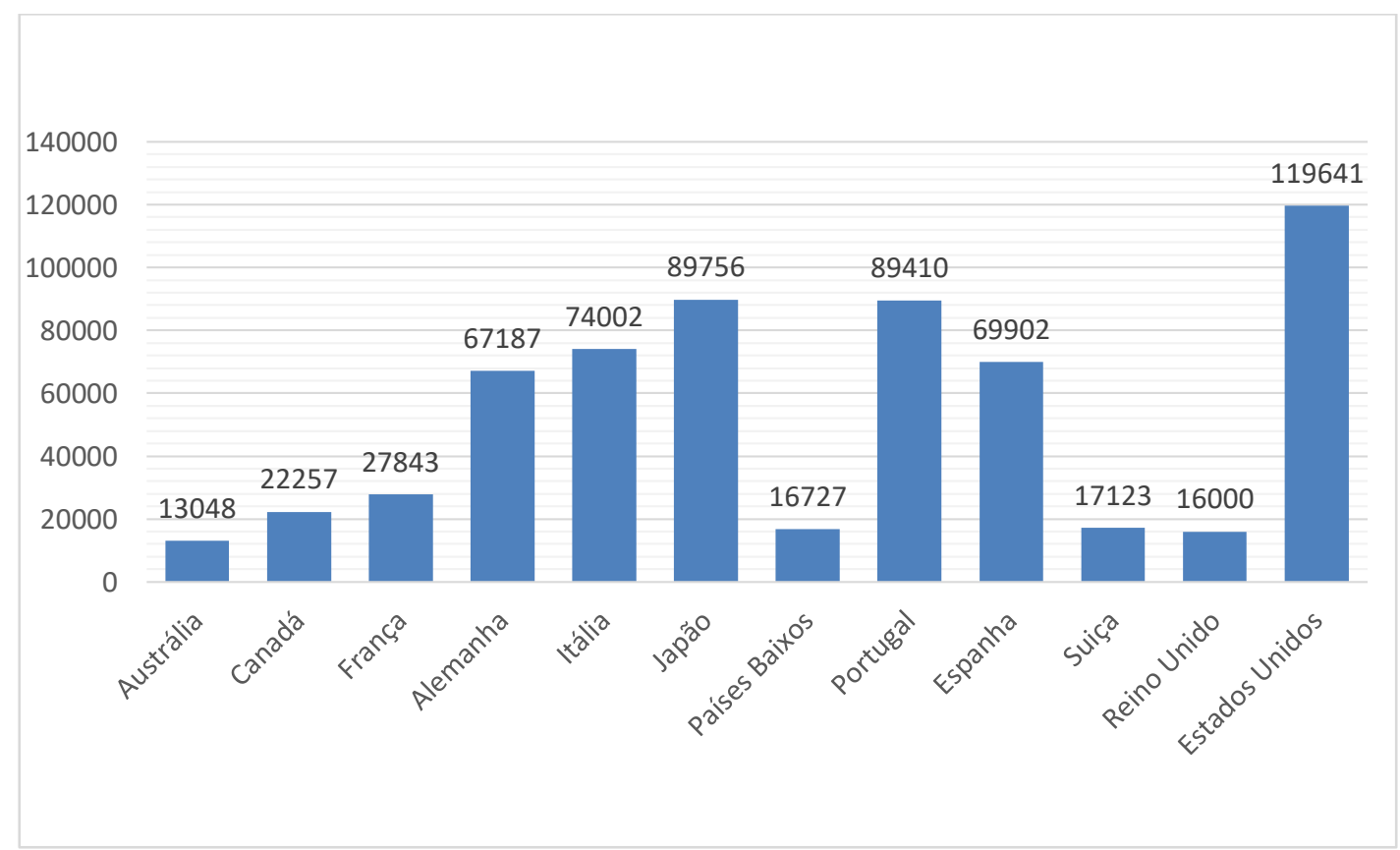

Fonte: OECD, 2021.

No que diz respeito a Portugal, país de delimitação do presente estudo, a OCDE contabilizou 89.410 imigrantes brasileiros, no período citado, assumindo a terceira posição entre os países de escolha dos brasileiros, atrás dos Estados Unidos (119.641) e Japão (89.756). O Gráfico II apresenta a evolução da imigração de brasileiros para Portugal, conforme registros da OCDE, no período de 2011 a 2018.

Gráfico II: Imigração de brasileiros para Portugal (2011-2018)

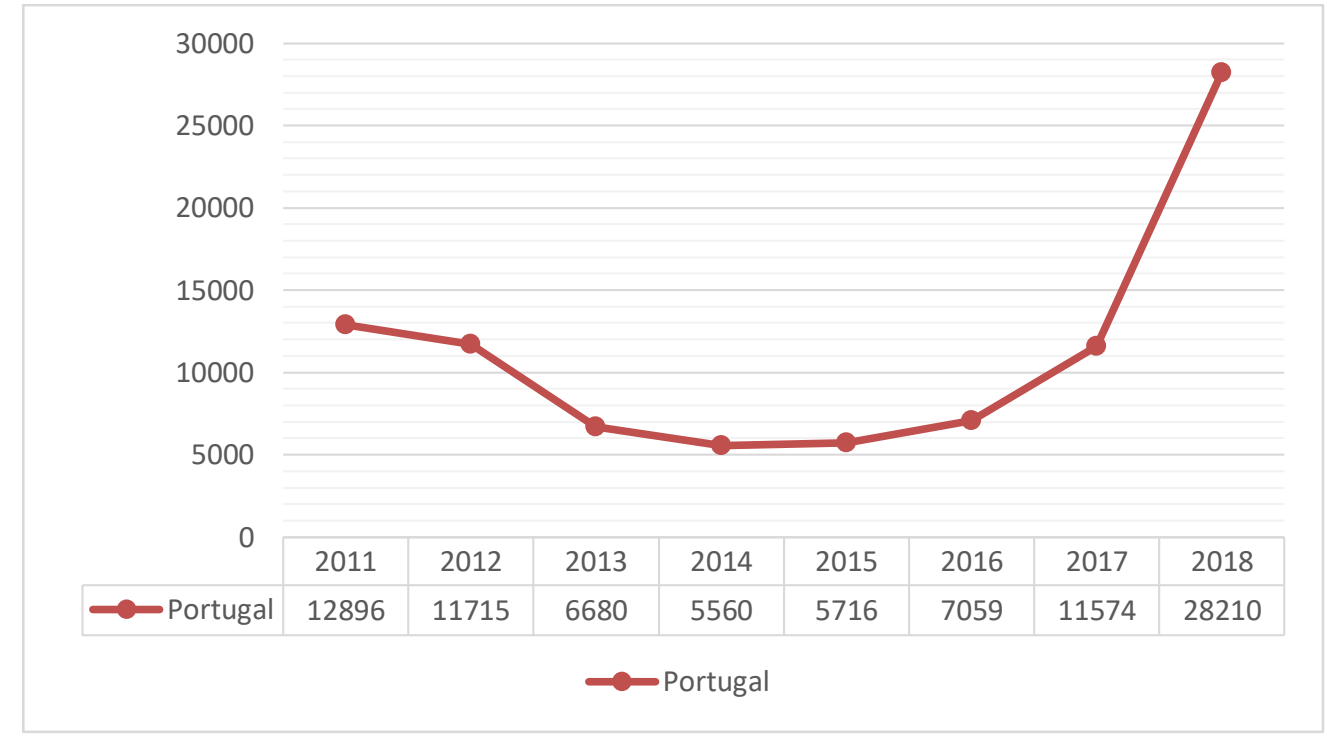

Fonte: OECD, 2021.

Caderno Eletrônico de Ciências Sociais, Vitória, v. 9, n. 1, pp. 68-91, 2021. 
Em 2011, foram registradas 12.896 entradas de brasileiros no país. Observa-se, contudo, um declínio na imigração nos anos seguintes, tendo o país recebido, em 2014, 5.560 brasileiros, o que corresponde a menos da metade de brasileiros contabilizados em 2011 e o menor número de todo o período avaliado. A curva da imigração voltou a demonstrar crescimento a partir de 2015, ainda de modo comedido, tendo um salto expressivo de ascensão entre 2017 e 2018. No último ano avaliado, o número de estrangeiros brasileiros residentes em Portugal mais que dobrou, passando de 12.896, em 2011, para 28.210, em 2018.

O Relatório de Emigração, Fronteiras e Asilo 2020, realizado pelo SEF, aponta que, atualmente, Portugal possui em sua população 662.095 cidadãos estrangeiros residentes, um aumento de $12,2 \%$, em relação ao ano anterior, e o maior número registrado desde 1976, ano de surgimento da entidade. Pelo quinto ano consecutivo (2015-2020), houve um crescimento considerável no número de imigrantes, passando de 388.731, em 2015, para 662.095, em 2020. Destaca-se o ano de 2019, cuja a população estrangeira teve um crescimento de $22,9 \%$, em comparação a 2018. Tal fato se deve ao aumento do Produto Interno Bruto (PIB); e, em particular, à maior oferta de trabalho no país, no período avaliado (SERVIÇO DE ESTRANGEIROS E FRONTEIRAS, 2020a).

Entre as nacionalidades de maior representatividade em Portugal, o Brasil ocupa a primeira posição, com 183.993 brasileiros, o que constitui $27,8 \%$ da população total estrangeira residente no país, à frente da segunda posição, o Reino Unido, que possui $7 \%$ de imigrantes (46.238). Índia (39,3\%), Reino Unido $(34,6 \%)$ e Brasil $(21,6 \%)$ são os três países com crescimento mais significativo de imigrantes em Portugal, enquanto Cabo Verde, Romênia, Ucrânia e China apresentaram declínio no número de imigrantes, em 2020, em comparação ao ano anterior.

Caderno Eletrônico de Ciências Sociais, Vitória, v. 9, n. 1, pp. 68-91, 2021. 
Migração brasileira para a área metropolitana de Lisboa: análise e interpretação dos dados

Criada pela Lei no 44/91, de 2 de agosto de 1991, a Área Metropolitana de Lisboa (AML) possui $3.015 \mathrm{~km}^{2}$ de extensão territorial, 3,3\% da área total de Portugal. Trata-se de pessoa coletiva de direito público de âmbito territorial, cujo objetivo precípuo é atender aos interesses da população dos seus dezoito concelhos integrantes: Alcochete, Almada, Amadora, Barreiro, Cascais, Lisboa, Loures, Mafra, Moita, Montijo, Odivelas, Oeiras, Palmela, Seixal, Sesimbra, Setúbal, Sintra e Vila Franca de Xira (PORTUGAL, 1991; INSTITUTO NACIONAL DE ESTATÍSTICA, 2021a). No mapa abaixo é possível visualizar a distribuição dos concelhos:

Figura 1: Mapa da Área Metropolitana de Lisboa.

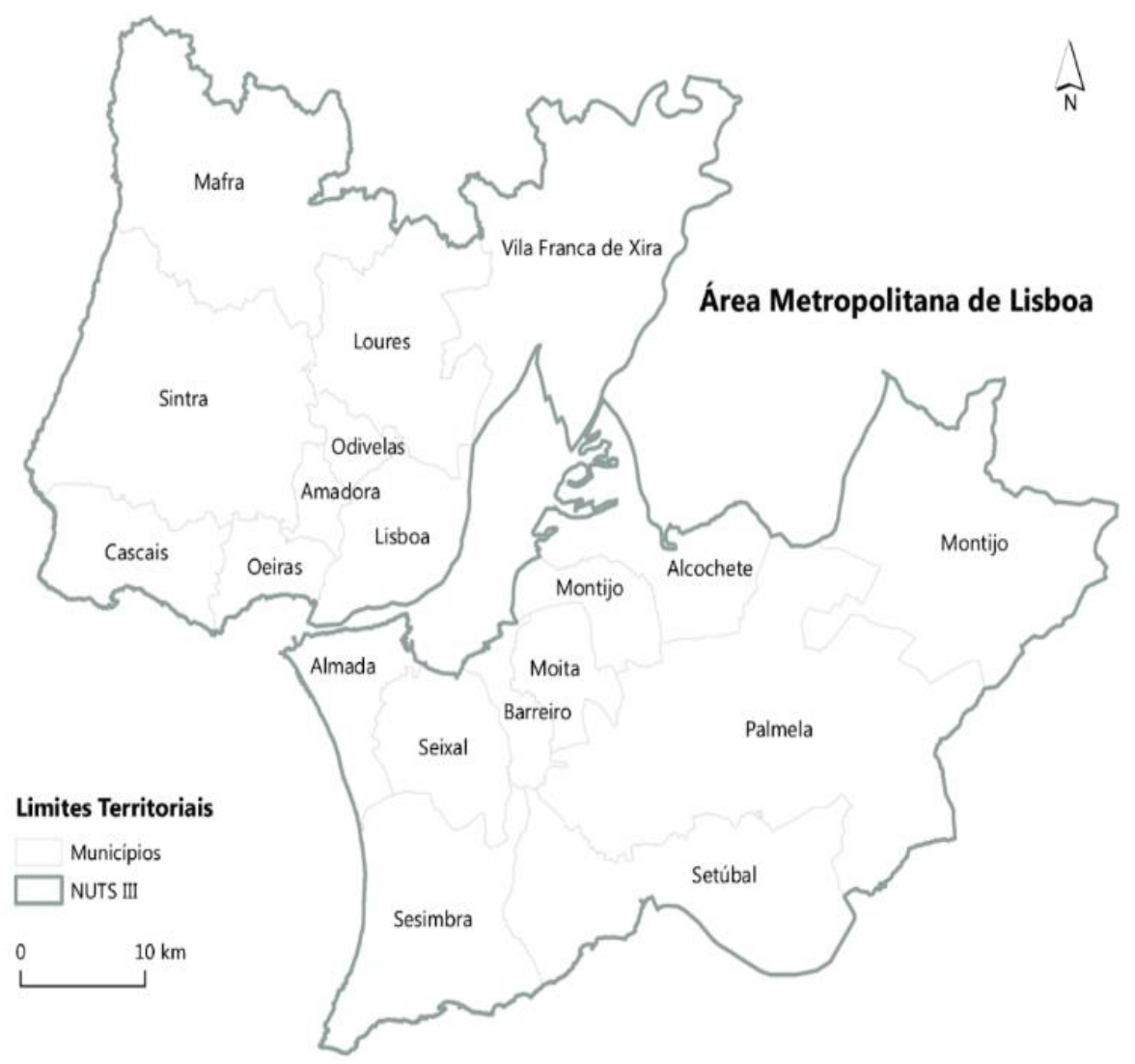

Fonte: Instituto Nacional de Estatística, 2019. 
A AML faz parte da Nomenclatura das Unidades Territoriais para Fins Estatísticos (NUTS) II e III. A NUTS foi criada pelo Eurostat, no início da década de 1970, com o objetivo de unificar as estatísticas de vários países da União Europeia, no que diz respeito à coleta, compilação e publicação dos dados regionais. A nomenclatura encontra respaldo jurídico no Regulamento Comunitário no 1059/2003, o qual estabelece procedimento padrão a ser seguido pelos Estados-Membros (EM), quando da necessidade de mudanças das unidades territoriais para fins estatísticos. Cada EM é subdividido em 3 níveis, sendo o primeiro critério de subdivisão a população das unidades administrativas. Assim, a NUTS I possui como vetor de dimensão demográfica o mínimo de 3 milhões e o máximo de 7 milhões de habitantes; a NUTS II, o mínimo de 800 mil e o máximo de 3 milhões de habitantes; NUTS III, o mínimo de 150 mil e o máximo de 800 mil habitantes (INSTITUTO NACIONAL DE ESTATÍSTICA, 2015; FUNDAÇÃO FRANCISCO MANOEL DOS SANTOS, 2013).

Razões de ordem geográfica, socioeconômica, cultural, dentre outras, permitem uma subdivisão regional de modo diferenciado. É o exemplo da versão NUTS 2013 portuguesa, que, ao invés do critério populacional para subdivisão regional, adota o critério territorial, a partir da Reforma da Administração Local, com destaque à criação das Entidades Intermunicipais pela Lei no 75, de 12 de setembro de 2013, consideradas, a partir de então, unidades administrativas. A NUTS I portuguesa não sofreu alterações pela reforma NUTS 2013, em comparação à NUTS 2003, sendo constituída pelo Continente, Região Autônoma dos Açores e Região Autônoma da Madeira. A NUTS II não teve modificações territoriais, abrangendo, assim, as 7 regiões anteriores: Norte, Centro, Área Metropolitana de Lisboa, Alentejo, Algarve, Região Autônoma dos Açores e Região Autônoma da Madeira. Todavia, a designação NUTS Lisboa foi alterada para Área Metropolitana de Lisboa, agora pertencente às NUTS II e III, como se viu. A NUTS III foi a mais afetada pelas alterações. Passou de 30 para 25 regiões. 8 regiões não sofreram alterações geográficas. Minho-Lima passou a ser designado Alto Minho. Em 13 regiões,

Caderno Eletrônico de Ciências Sociais, Vitória, v. 9, n. 1, pp. 68-91, 2021. 
houveram alteração dos limites territoriais e 12 NUTS III receberam nova designação (INSTITUTO NACIONAL DE ESTATÍSTICA, 2015).

Em 31/12/2019, a população residente da AML era de 2.863.272 habitantes, sendo a maior parte da população constituída por mulheres (1.525.852). A população masculina perfaz o total de 1.337.420. A AML é responsável por grande parte da economia do país, tendo em seu território 366.627 empresas nacionais contribuindo com 1.416 .153 postos de empregos e $36 \%$ do PIB nacional. A área é responsável, também, por 31,3\% das exportações e $51,8 \%$ das importações realizadas no país. O comércio de produtos da $\mathrm{AML}$ para países europeus e aqueles não pertencentes ao grupo tem grande relevância. Em 2019, 29,2\% das exportações e 49,8\% das importações de Portugal para um dos países Intra União Europeia foram realizadas por intermédio do comércio da AML. Em relação à comercialização de produtos entre países Extra União Europeia, a exportação atingiu o patamar de $38,0 \%$ e a importação de 58,6\% (INSTITUTO NACIONAL DE ESTATÍSTICA, 2021b).

O Gráfico III apresenta a evolução da população estrangeira em geral, em relação à população estrangeira brasileira, na $\mathrm{AML}$, nos últimos anos.

Gráfico III: Relação entre população estrangeira e brasileira na AML (2011-2020)

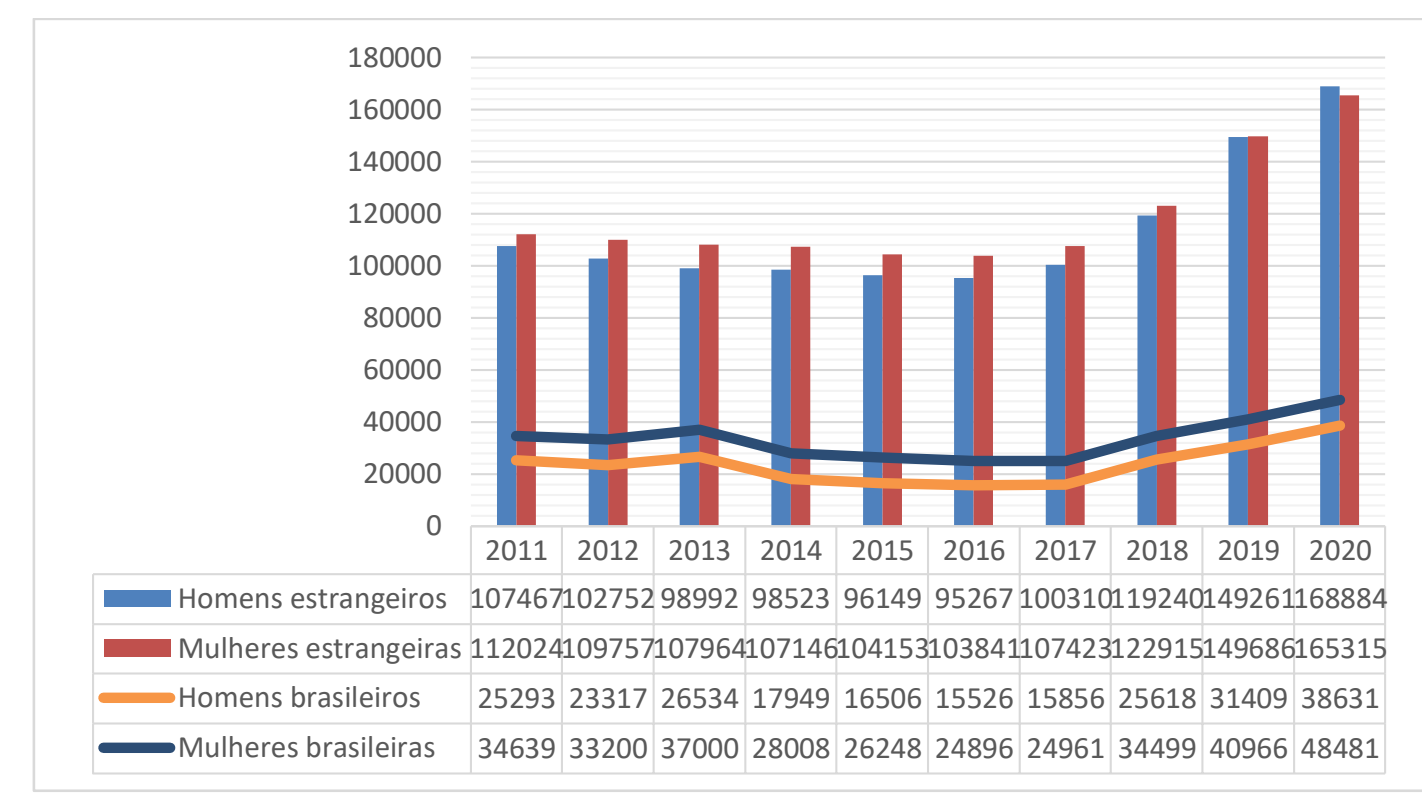

Fonte: Serviço de Estrangeiros e Fronteiras, 2020b

Caderno Eletrônico de Ciências Sociais, Vitória, v. 9, n. 1, pp. 68-91, 2021. 
A análise do Gráfico $V$ permite identificar que o número de mulheres estrangeiras na Área Metropolitana de Lisboa foi maior do que o número de homens estrangeiros em todos os períodos, com exceção do ano de 2020 - ano em que a diferença positiva de homens foi de apenas 3.569. Considerando que em 2020 o número de brasileiras na AML superou em 9.850 o número de brasileiros, vale dizer, mesmo em um período em que a imigração feminina em geral para a AML apresentou declínio, as mulheres brasileiras mantiveram sua preponderância. Pode-se afirmar, ainda, que, em 2020, a AML recebeu 165.315 imigrantes mulheres estrangeiras, frente a 168.884 imigrantes de sexo masculino.

O Gráfico IV representa a evolução de brasileiros homens e mulheres na AML nos últimos anos, ora veja-se:

Gráfico IV: Relação entre população estrangeira e brasileira na AML (2011-2020).

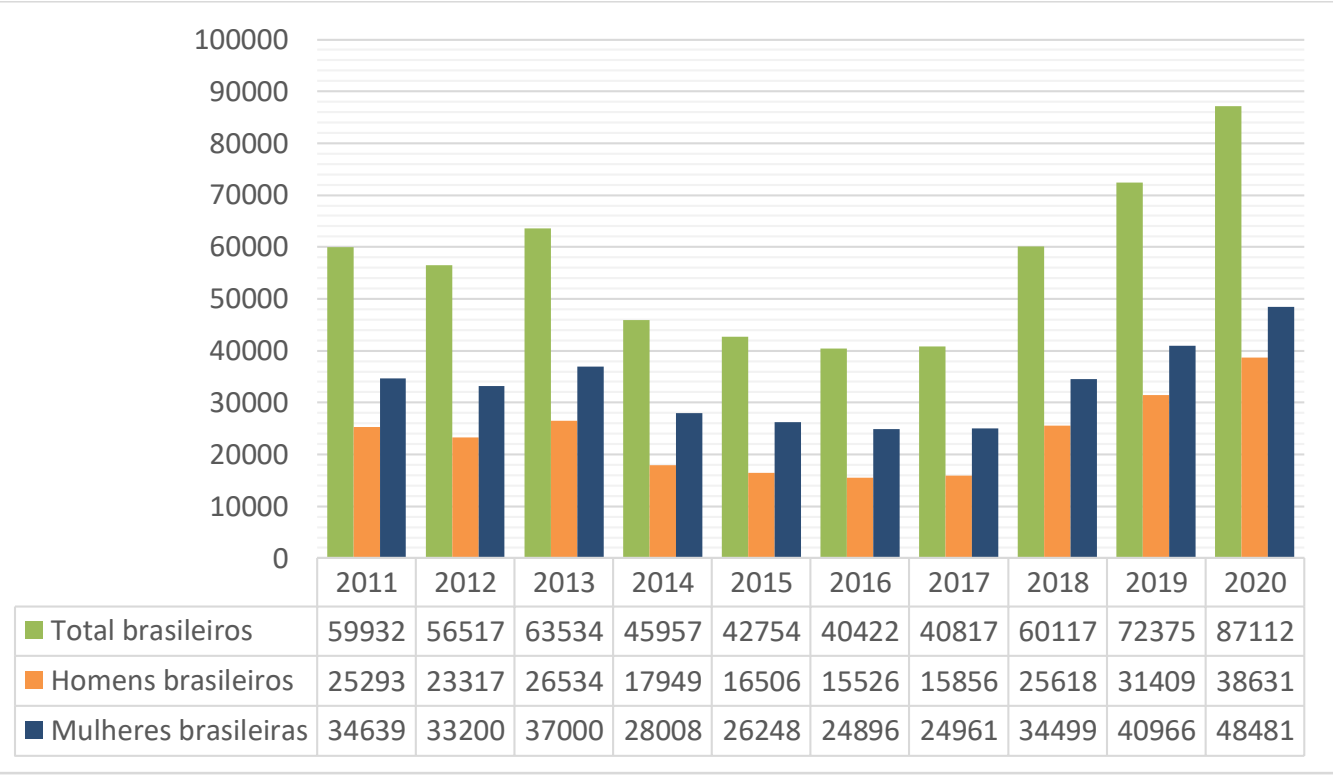

Fonte: Serviço de Estrangeiros e Fronteiras, 2020b.

No que se refere ao número de brasileiros imigrantes na $A M L$, as mulheres foram maioria em todos os períodos analisados, com uma diferença significativa. Em 2013, por exemplo, foram 10.466 mulheres brasileiras a mais do que homens brasileiros. A menor diferença positiva se deu em 2018, quando as mulheres superaram os homens em 8.881. Sobre o volume total de brasileiros na $\mathrm{AML}$, não é possível identificar variações extraordinárias até o ano

Caderno Eletrônico de Ciências Sociais, Vitória, v. 9, n. 1, pp. 68-91, 2021. 
de 2019, quando o volume ultrapassou a máxima de 2013 (63.534 imigrantes), chegando a 72.375 - uma diferença de 8.841. No ano seguinte, em 2020, o volume apresentou outro salto, ainda mais importante, para 87112 imigrantes 14.737 em comparação ao ano anterior.

Ao analisar o número de brasileiros com Título de Residência (TR) e com Visto de Longa Duração (VLD), percebe-se uma constante no que se refere a proporção entre esses documentos. Os VLDs são irrisórios quando comparados aos TRs, que representam mais de $98,919 \%$, no mínimo. Com exceção dos anos de 2015 e 2017, nos demais períodos a taxa de brasileiros com TRs permaneceu acima dos 99\% (SERVIÇO DE ESTRANGEIROS E FRONTEIRAS, 2020b).

\section{Conclusões}

Conforme apresentado ao longo do artigo, a imigração para Portugal pode ser analisada a partir de três grandes momentos, que representam fluxos imigratórios ao longo dos anos. Enquanto o primeiro fluxo se constituiu de imigrantes altamente qualificados, que passaram a ocupar posições laborais de destaque, os fluxos seguintes, além de maiores, foram responsáveis pela inserção de trabalhadores em postos menos qualificados, principalmente setores de serviço e construção civil.

Portugal é a terceira principal escolha dos brasileiros que buscam a imigração, ficando atrás apenas dos Estados Unidos e Japão, sendo esse um dos fatores que explicam a predominância de brasileiros entre os estrangeiros em Portugal. O segundo colocado, o Reino Unido, contava com apenas $7 \%$ de imigrantes em Portugal no mesmo período.

A Área Metropolitana de Lisboa (AML), apesar de ocupar pequena parcela territorial, apresenta grande relevância para Portugal, especialmente no que se refere a economia do país, contribuindo com $36 \%$ do PIB nacional. No ano de 2019 a região contava com uma população de 2.863.272 habitantes, incluindo 
298.947 residentes estrangeiros. Entre os estrangeiros, por sua vez, destaque para o contingente brasileiro, com 72.375 imigrantes no mesmo período.

As informações teóricas, bem como os dados estatísticos apresentados, permitem concluir no sentido de que a imigração de brasileiros para Portugal é motivada por uma série de fatores, dentre os quais se destacam a busca por melhores condições de vida, tendo em vista a violência, a insegurança políticoeconômica, a corrupção e condições de vida desfavoráveis no Brasil. Por outro lado, Portugal demonstrou, historicamente, situação atrativa para os imigrantes brasileiros, a exemplo da estabilidade política e econômica e aumento da oferta de empregos. A proximidade cultural, os laços históricos e os processos de regularização extraordinária, por sua vez, impulsionaram ainda mais a imigração brasileira.

Ante o exposto, chega-se ao entendimento de que a imigração de brasileiros para Portugal, de modo geral, e para a Área Metropolitana de Lisboa $(A M L)$, de modo específico, é notável. A análise dos dados aponta para um crescimento exponencial do número de imigrantes brasileiros na AML nos últimos anos. As limitações de circulação internacional impostas pela pandemia do Covid devem afetar os números atuais, principalmente no que se refere ao ingresso de novos imigrantes.

No entanto, essa circunstância não deve frear o movimento de busca por oportunidades no país, como alternativa à realidade brasileira, marcada pela violência, insegurança e outras mazelas. Se no Brasil não se alteram as condições socioeconômicas que vêm determinando o processo de emigração nos últimos anos, não há elementos que sugiram que esse fenômeno não continue a crescer nos próximos anos.

Caderno Eletrônico de Ciências Sociais, Vitória, v. 9, n. 1, pp. 68-91, 2021. 


\section{Referências bibliográficas}

ABAD, L. V. M. 2002. Contradições da globalização: migrações e convivência interétnica após 11 de setembro. Revista Migraciones, n. 11.

AYER, F. 2019. Mudança de 21,8 mil brasileiros para o exterior até julho supera quase toda a saída em 2018. Disponível em: https://www.em.com.br/app/noticia/politica/2019/08/10/interna_politica,10 76303/mudanca-de-21-8-mil-brasileiros-para-o-exterior-ate-julho-superaquase.shtml. Data de acesso: 19 jul. 2021.

BLANCO, C. 2000. Migrações Contemporâneas. Madrid: Aliança Editorial.

BRASIL. 2020. Atlas da violência: 2020. Disponível em: https://www.ipea.gov.br/portal/index.php?option=com_content\&view=articl e\&id=36488\&Itemid=432. Data de acesso: 20 jul. 2021.

BRASIL. 2021. PNAD Contínua: Pesquisa Nacional por Amostra de Domicílios Contínua. Disponível em: https://www.ibge.gov.br/estatisticas/sociais/trabalho/9173-pesquisanacional-por-amostra-de-domicilios-continua-trimestral. html? $=\& \mathrm{t}=$ serieshistoricas\&utm_source=landing\&utm_medium =explica\&utm_campaign=des emprego. Data de acesso: 20 jul. 2021.

COSTA, P. L. 2011. A mobilidade socioespacial dos imigrantes: o caso dos brasileiros, ucranianos e guineenses, em Portugal. (Tese). Porto: Faculdade de Letras da Universidade do Porto. Disponível em: https://repositorio-aberto.up.pt/handle/10216/57469. Data de acesso: 14 nov. 2021.

FERNANDES, D. 2019. País sobe em ranking de países que mais enviam imigrantes para nações ricas. Disponível em: https://www.bbc.com/portuguese/internacional-49731607. Data de acesso: 3 jul. 2021.

FERNANDES, D. et al. 2021. A quarta onda da imigração brasileira em Portugal: uma história breve. Revista Latinoamericana de Población, v. 15, pp. 34-63, 2021.

FUNDAÇÃO FRANCISCO MANOEL DOS SANTOS. 2013. O que são NUTS?. Disponível em: https://www.pordata.pt/O+que+sao+NUTS. Data de acesso: 8 jul. 2021.

G1. 2021. Monitor da violência. Disponível em: https://especiais.g1.globo.com/monitor-da-violencia/2018/mortesviolentas-no-brasil/?_ga =2.121205320.133710473.1581420662-cfa2b15e-

Caderno Eletrônico de Ciências Sociais, Vitória, v. 9, n. 1, pp. 68-91, 2021. 
db45-d55b-b882-86a5ddd586a2\#/dados-mensais-2020. Data de acesso: 20 jul. 2021.

GARCIA, J. L. B. et al. 1993. Migrações e saúde mental. Barcelona: Promoções e Publicações Universitárias PPU.

GERBELLI, L. G. 2019. Cresce número de brasileiros que decidem viver no exterior; países oferecem oportunidades de emprego. Disponível em: https://g1.globo.com/economia/concursos-eemprego/noticia/2019/04/03/cresce-numero-de-brasileiros-que-decidemviver-no-exterior-paises-oferecem-oportunidades-de-emprego.ghtml. Data de acesso: 19 jul. 2021.

GIL, A. C. 2008. Métodos e técnicas de pesquisa social. 6. ed. São Paulo: Atlas.

INSTITUTO NACIONAL DE ESTATÍSTICA. 2015. NUTS 2013: As novas unidades territoriais para fins estatísticos. Disponível em: https://www.ine.pt/xportal/xmain?xpid=INE\&xpgid=ine_publicacoes\&PUBLI CACOESpub_boui $=230205992 \&$ PUBLICACOESmodo=2\&xlang=pt. Data de acesso: 5 jul. 2021.

INSTITUTO NACIONAL DE ESTATÍSTICA. 2019. Anuário estatístico da Área Metropolitana de Lisboa: 2018. Lisboa: INE.

INSTITUTO NACIONAL DE ESTATÍSTICA. 2021a. Área Metropolitana de Lisboa em Números: In figures - 2019. Lisboa: INE.

INSTITUTO NACIONAL DE ESTATÍSTICA. 2021b. Área Metropolitana de Lisboa em números: 2019.2 Disponível em: https://www.ine.pt/xurl/pub/481533898. Data de acesso: 1 jul. 2021.

JOÃO, M. I. 2013. Breve panorama da imigração na Área Metropolitana de Lisboa (1980-2010). População e Sociedade, v. 21, pp. 197-215, 2013.

LAKATOS, E. M.; MARCONI, M. A. 2017. Fundamentos da metodologia científica. 8. ed. São Paulo: Atlas.

LARAÑA, E. 1993. Modelos de interpretación y cuestiones de gé-nero no estudo das migrações espanholas. Revista Política y Sociedad, Universidade Complutense de Madrid, n. 12, pp. 121-137.

LISBOA, W. T. 2016. Fluxos transatlânticos e indentidade: a imigração brasileira em Portugal e o imaginário português sobre o Brasil. Anais, pp. 1-15, 2016.

MASSEY, D. S. 1988. Economic development and international migration in comparative perspective. Population and Development Review, n. 14, pp. 383-413.

MASSEY, D. S. et al. 1998. Mundos em movimento. Entendendo a migração internacional no final do milênio. Oxford: Clarendon Press.

Caderno Eletrônico de Ciências Sociais, Vitória, v. 9, n. 1, pp. 68-91, 2021. 
MUNIZ, J. O. 2002. Um ensaio sobre as causas e características da migração. In: UFMG/Cedeplar/Demografia - Avaliação (Componentes de Dinâmica Demográfica).

NAKAGAWA, F. 2021. Com crise e desemprego, mais de 130 mil brasileiros deixaram 0 Brasil em 2021. Disponível em: https://g1.globo.com/economia/concursos-eemprego/noticia/2019/04/03/cresce-numero-de-brasileiros-que-decidemviver-no-exterior-paises-oferecem-oportunidades-de-emprego.ghtml. Data de acesso: 20 jul. 2021.

NUNAN, C.; PEIXOTO, J. 2012. Crise econômica e retorno dos imigrantes brasileiros em Portugal. Revista Interdisciplinar da Mobilidade Humana, v. 20, pp. 233-250, 2012.

OECD - ORGANISATION FOR ECONOMIC CO-OPERATION AND DEVELOPMENT. 2021. Banco de dados de migração internacional: Brasil. Disponível em: https://stats.oecd.org/index.aspx?datasetcode=pop_five_hist. Data de acesso: 15 jul. 2021.

OLIVEIRA, E. N. et al. 2017. Migration, quality of life and health of brazilian immigrants in Portugal. International Archives of Medicine Section: Psyquiatry \& Mental Health, v. 10, n. 158.

PATARRA, N. L. 2006. Migrações internacionais: teorias, políticas e movimentos sociais. Revista Estudos Avançados, São Paulo. v. 20, n. 57, pp. 7-24.

PEIXOTO, J.; EGREJA, C. 2012. A força dos laços fracos: estratégias de emprego entre os imigrantes brasileiros em Portugal. Tempo Social, v. 24, pp. 263-282, 2012.

PEREIRA, N. L. S. L. F. 2019. A hipótese predatória como elemento decisivo na emigração de brasileiros. (Dissertação). Porto: Universidade do Porto.

PEREIRA, S.; ESTEVES, A. 2017. Os efeitos da crise econômica na situação laboral dos imigrantes: o caso dos brasileiros em Portugal. Revista Interdisciplinar da Mobilidade Humana, v. 25, pp. 135-152, 2017.

PINHO, F. 2014. Transformações na emigração brasileira para Portugal: de profissionais a trabalhadores. Lisboa: Alto-Comissariado Para as Migrações.

PORTUGAL. 1991. Lei no 44/91. Disponível em: https://dre.pt/pesquisa//search/686608/details/maximized. Data de acesso: 10 jul. 2021.

PRODANOV, C. C.; FREITAS, E. C. 2013. Metodologia do trabalho científico: métodos e técnicas da pesquisa e do trabalho acadêmico. 2. ed. Novo Hamburgo: Feevale.

RODRIGUES, A. J. et al. 2011. Metodologia científica. Aracajú: Unit. 
SASSEN, S. 1998. As cidades na economia mundial. São Paulo: Studio Nobel.

SERVIÇO DE ESTRANGEIROS E FRONTEIRAS. 2020a. Relatório de Imigração, Fronteiras e Asilo: 2020. Oeiras: SEF.

SERVIÇO DE ESTRANGEIROS E FRONTEIRAS. 2020b. Estrangeiros residentes: Lisboa. Disponível em: https://sefstat.sef.pt/forms/distritos.aspx. Data de acesso: 15 jul. 2021.

TRUZZI, O. 2011. Redes em processos migratórios. In: LANNA, A. L. D. et al. (orgs.). São Paulo, os estrangeiros e a construção das cidades. São Paulo: Alameda. 